\title{
Adsorption of Polyethyleneimine on Silver Nanoparticles and Its Interaction with a Plasmid DNA: A Surface-Enhanced Raman Scattering Study
}

\author{
S. Sanchez-Cortes, ${ }^{*}, \dagger$ R. Marsal Berenguel, ${ }^{\ddagger}$ A. Madejón,§ and M. Pérez-Méndez ${ }^{\ddagger}$ \\ Instituto de Estructura de la Materia, CSIC, Serrano, 121, 28006 Madrid, Spain, \\ Instituto de Ciencia y Tecnología de Polímeros, CSIC, Juan de la Cierva, 3, 28006 Madrid, Spain, and \\ BIOTOOLS B\&M Labs., S.A., Valle de Tobalina, 52, 28021 Madrid, Spain
}

Received November 13, 2001; Revised Manuscript Received February 22, 2002

\begin{abstract}
Raman spectroscopy is applied in this work to study the adsorption of poly(ethyleneimine) (PEI) on Ag nanoparticles obtained by reduction with citrate, as well as to the study of the interaction between PEI and a plasmid. The surface-enhanced Raman spectroscopy (SERS) affords important information about the interaction and orientation of the polymer on the particles. In particular we have found that this polymer interacts with the surface through their amino groups in an interaction which also involves a change in the protonation state of amino groups as well as an increase of the chain order. This interaction implies a charge-transfer effect as deduced from the strong resonant effect in Raman spectra obtained at different excitation wavelengths. The complex formed by PEI and a plasmid, obtained by encoding the HBV (hepatitis $\mathrm{B}$ virus) genome inside the EcoRI restriction site of pGEM vector, was also studied by SERS. The interaction between both polymers leads to a conformational change affecting both macromolecules that can be detected by Raman at different excitation wavelengths. PEI undergoes a change to a more disordered structure as well as an increase of the number of protonated amino groups. The plasmid undergoes a structural change from A-DNA structure to B-DNA, along with a change in the superhelicity resulting in a more lineal structure when the plasmid interacts with PEI.
\end{abstract}

\section{Introduction}

The DNA condensing capacity of lipopolyamines was first described over a decade ago. ${ }^{1}$ The demostration that the DNA/lipid complexes so formed could be used for cellular transfection was followed 3 years later. $^{2}$ The complex formation between DNA and cationic lipids or polymers as transfection vectors is a process which is still largely empirical and uncontrolled. Basically, polycationic molecules, with a large amount of intramolecular positive charges, will repel each other, thus extending the molecule and optimizing counterion collapse on interaction with polyanionic DNA.

In vitro studies with both cationic lipids and cationic polymers reveal the electrostatic interactions between the negatively charged glycosaminoglycans of the cell membranes and the positively charged DNA/vector complexes, with an overall resulting positive charge. This interaction is enhanced by increasing the overall charge of the complexes with higher ratios of vector to DNA. ${ }^{3}$ Polyethyleneimine (PEI), Figure 1, is a cationic polymer in which one in every third atom is an amino nitrogen that can be protonated (the $\mathrm{C}: \mathrm{N}$ ratio is $2: 1$ ). In fact, $\mathrm{PEI}$ is the cationic polymer having

* To whom correspondence should be addressed. Fax: + 349156455 57. Phone: + 349156168 00. E-mail: imts158@iem.cfmac.csic.es.

$\dagger$ Instituto de Estructura de la Materia, CSIC.

Instituto de Ciencia y Tecnología de Polímeros, CSIC.

$\S$ BIOTOOLS B\&M Labs., S.A.

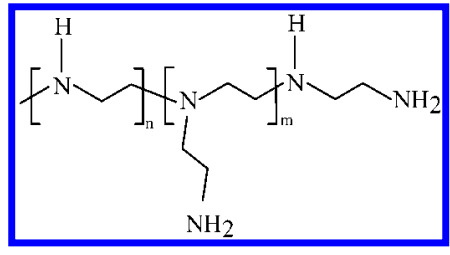

Figure 1. Structure of PEI.

the highest charge density potential, its overall protonation level increasing from 20 to $45 \%$ between $\mathrm{pH} 7$ and 5.,5

Since the adsorption of the PEI/DNA complex to a negative surface is a process of a great importance in relation to the DNA release and incorporation by the cell, the study of structural changes derived from this adsorption is also crucial in the investigation of the vector effectiveness. In this sense, surface-enhanced Raman scattering (SERS) is nowadays an active area with a broad range of analytical applications which can be successfully applied in the study of interfacial phenomena. Since its discovery, ${ }^{6}$ SERS has become a technique of common use for analyzing the adsorption of molecules on surfaces. Although this technique is based on the enormous enhancement of the electromagnetic field occurring in the vicinity of metallic nanoparticles, mainly of $\mathrm{Ag}$ and $\mathrm{Au},{ }^{7}$ it has been also suggested by the existence of a chemical contribution to explain the overall SERS enhancement related to a charge transfer between the adsorbate and the metal surface. ${ }^{8}$ The short-range enhancement occurring in SERS can be used to investigate the electrodynamical behavior of organic molecules adsorbed on 
charged surfaces, due to the predominant enhancement of those vibrational modes which are closer to the metal, thus providing a very valuable information regarding the structure of the adsorbed molecules. ${ }^{9}$ The colloids employed in this work are integrated by metallic silver particles surrounded by an excess of citrate employed in the preparation of the colloid, ${ }^{10}$ thus, with a net negative charge in the surface. Therefore, the SERS technique may be applied to investigate the chemical state of cationic polymers on an anionic surface simulating the anionic surfaces of cells, where a similar adsorption and interaction phenomena may also occur.

The transfection ability of PEI/plasmid complexes has been investigated so far in a number of works. ${ }^{11-14}$ Vibrational spectroscopies are very suitable techniques to carry out structural studies in biomolecules and polymers with significant biological importance. However, these techniques have not been applied, up to now, to characterize the recognition ability of PEI in relation to DNA. Therefore, the aim of this work was to conduct a Raman study of the adsorption of PEI on a citrate-reduced silver colloid and of the interaction of PEI with a plasmid. The spectroscopic study was carried out by paying special attention to the structural changes occurring in PEI and in the plasmid after the adsorption and complexation. The utility of SERS in the study of the PEI/DNA system was double. By one hand it makes possible the Raman study at very low concentrations of the biomacromolecules, close to those at which they are in the physiological environment. On the other hand, for heterogeneous systems, as it is the case of these complexes, where multiple interactions are possible, the citrate-covered metals are substrates on which PEI is strongly attached, thus selecting the DNA under study to those sequences which are directly involved in the interaction with the polyamine, since the SERS enhancement is higher just for those molecular groups closer to the surface.

\section{Experimental Part}

Materials. Branched polyethylenimine, 50\% (w/v) aqueous solution (average $M_{\mathrm{w}}=750000$ ), was purchased from Sigma-Aldrich Chemie, Gmbh, Steinheim, Germany. The cloned plasmid was supplied by Biotools. It contained 9.4 $\mathrm{kb}$ and was composed by a pGEM vector (commercial) where two complete HBV (hepatitis B virus) genome copies were inserted in the EcoRI restriction site.

Preparation of Samples. Silver colloids for SERS measurements were prepared by the Lee-Meisel method ${ }^{15}$ by the following way: $200 \mathrm{~mL}$ of a $10^{-3} \mathrm{M} \mathrm{AgNO}_{3}$ aqueous solution was heated to the boiling point, $4 \mathrm{~mL}$ of a $1 \%$ trisodium citrate solution was then added, and the mixture was boiled for $1 \mathrm{~h}$. Triply distilled water was employed in the preparation of all the solutions.

The silver colloids prepared in this way displayed an extinction band centered at $430 \mathrm{~nm}$. This band has been predominantly assigned to particles having a spherical or spheroidal shape with a diameter between 30 and $60 \mathrm{~nm}$, with an average diameter of $45 \mathrm{~nm}$. In previous works we have accomplished a detailed optical and microscopic study of these colloids. ${ }^{16,17}$
Samples for SERS measurements were obtained by mixing $1.7 \mu \mathrm{L}$ of a $10 \mathrm{mM}$ PEI aqueous solution with $5 \mu \mathrm{L}$ of a $0.12 \mathrm{mg} / \mathrm{mL}$ aqueous solution of the plasmid. This mixture ensured a nitrogen to phosphorus ratio of 9:1 in the PEI and DNA, respectively, according to the polyethylenimine transfection method described by Boussif et al. in eucariotic cells. ${ }^{18}$ The complex was kept during at least $1 \mathrm{~h}$ before taking the measurement in order to ensure a complete interaction of the DNA with PEI. Samples for SERS measurements of PEI or the plasmid were obtained by adding the same volume of water as that of the other component employed to prepare the complex. The Ag colloid was activated prior to being added to the complex. This activation consisted of the colloid aggregation, necessary for observing a strong SERS spectrum, and which was accomplished by adding aliquots of an aqueous potassium nitrate solution (5 $\times 10^{-1} \mathrm{M}$ ) up to a $10 \mathrm{mM}$ final concentration. Afterward, $200 \mu \mathrm{L}$ of the activated Ag colloid was added to the above complex solution. Aliquots of $5-6 \mu \mathrm{L}$ were put in $2 \mathrm{~mm}$ diameter glass capillaries to obtain the SERS spectra at different excitation wavelengths.

Instrumentation. Normal Raman spectra were recorded in a U-1000 Jobin-Yvon spectrophotometer by exciting with the $514.5 \mathrm{~nm}$ radiation line of a Spectra Physics model 165 argon ion laser equipped with a thermoelectrically cooled Products for Research, Inc., photon counting system photomultiplayer tube. The resolution was set at $4 \mathrm{~cm}^{-1}$, and a $90^{\circ}$ geometry was used to record the data. The laser power on the sample was fixed at $30 \mathrm{~mW}$. The spectra reported in this work were recorded at $1 \mathrm{~cm}^{-1}$ step intervals with an integration time of $1 \mathrm{~s}$. Four to five scans were averaged to obtain the SERS spectra shown in this work. The resulting spectra were smoothed by using the Savitzky-Golay algorithm and 13 smoothing points.

The Raman obtained with the $782 \mathrm{~nm}$ line was obtained in a Renishaw Raman microscope system RM1000 equipped with a Leica microscope and a CCD camera. The spectra shown here were obtained by using a $20 \times$ objective. The sample was placed in a glass capillary, and a laser power of $25 \mathrm{~mW}$ was employed. Ten scans of $10 \mathrm{~s}$ each were averaged to obtain the final spectrum.

FT-Raman spectra were obtained by using a RFS 100/S Brucker spectrophotometer equipped with a Ge detector cooled by liquid nitrogen. The $1064 \mathrm{~nm}$ line, provided by a $\mathrm{Nd}$ :YAG laser, was used as excitation line. Resolution was set to $4 \mathrm{~cm}^{-1}$, and a $180^{\circ}$ geometry was employed. The laser power at the sample was $150 \mathrm{~mW}$. The FT-SERS spectra shown here were the result of accumulating 1000 scans during $20 \mathrm{~min}$. The resulting FT-Raman spectra are shown without smoothing.

\section{Results and Discussion}

Adsorption of the PEI on Ag Nanoparticles. In Figure 2 the Raman spectrum of PEI is shown, together with the SERS spectra of the polymer adsorbed on $\mathrm{Ag}$ colloid registered at different excitation wavelengths. The Raman spectrum shows an intense band at $1456 \mathrm{~cm}^{-1}$ that is clearly attributed to $\mathrm{CH}_{2}$ bending. Other bands appearing at 1306, 


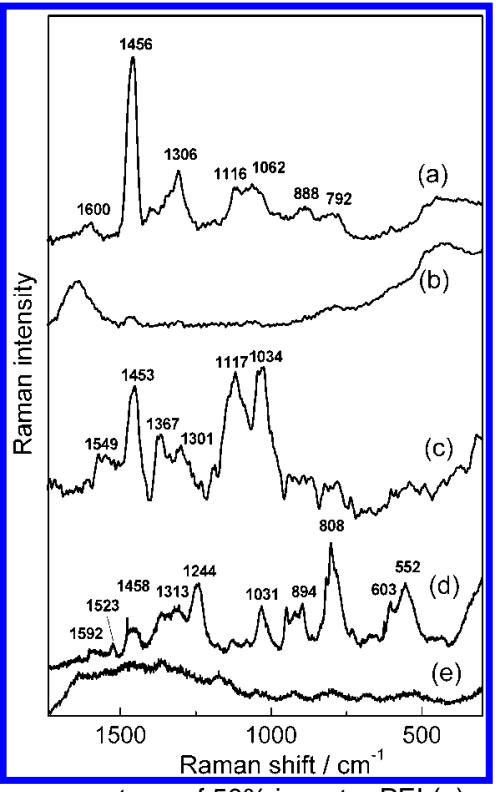

Figure 2. Raman spectrum of $50 \%$ in water $\mathrm{PEI}$ (a) and $10 \mathrm{mM} \mathrm{PEI}$ (b). SERS spectra of PEI $\left(8 \times 10^{-5} \mathrm{M}\right)$ exciting at $1064 \mathrm{~nm}$ (c), 782 $\mathrm{nm}(\mathrm{d})$, and $514.5 \mathrm{~nm}(\mathrm{e})$.

1116 , and $1062 \mathrm{~cm}^{-1}$ are also attributed to methylene groups, in particular to $\mathrm{CH}_{2}$ wagging and twisting motions, because these bands are also found in Raman spectra of polyethylene ${ }^{19}$ and ethylenediamine. ${ }^{20}$ The weak bands observed at 888 and $792 \mathrm{~cm}^{-1}$ are most probable due to the rocking vibrations of ethylene groups. The band appearing at 1600 $\mathrm{cm}^{-1}$ is due to the amine bending $\left(\delta\left(\mathrm{NH}_{2}\right)\right)$.

The adsorption of PEI on the Ag colloid leads to a marked change in the Raman spectrum. In general, a relative intensity decrease is observed for the bands corresponding to the aliphatic moieties, while a relative intensification is observed for the bands appearing at 1549, 1367, and $1034 \mathrm{~cm}^{-1}$ in the SERS spectrum obtained when exciting at $1064 \mathrm{~nm}$ (Figure 2c). All the last bands can be attributed to protonated amino moieties of PEI, namely, $\delta(\mathrm{NH}), \nu(\mathrm{C}-\mathrm{N})$, and $\rho\left(\mathrm{NH}_{2}\right)$ vibrations in accordance to the data obtained for similar polyamines. ${ }^{21-24}$ According to the short-range effect deduced from the electromagnetic mechanism of SERS, ${ }^{25}$ this intensification is related to an approach of amino groups to the metal surface, thus indicating that the interaction of the polymer with the surface may take place through these groups. This interaction mechanism is the most probable one taking into account that the residual charge of the colloidal surface is negative and the positive charge of the polymer is localized on the amino/imino groups. The shift of the amino band from 1600 to $1549 \mathrm{~cm}^{-1}$ in the SERS spectrum suggests a change in the protonation state of these groups as a consequence of the interaction with the surface. Chaufer et al. ${ }^{26}$ studied the adsorption of PEI on $\mathrm{Zr}$ and deduced the formation of a Lewis acid-base interaction between the amine groups and the metal. This interaction is also probable in the case of $\mathrm{Ag}$ colloids, thus inducing the shift of the $\mathrm{NH}_{2}$ bending mode to lower wavenumbers. Besides, the polymer may undergo a possible conformational change upon adsorption on the surface that is mainly deduced from the analysis of the $\mathrm{C}-\mathrm{H}$ stretching region (Figure $4 \mathrm{a}$ and $\mathrm{b}$ ). The asymmetric $\left(v_{\mathrm{as}}\right)$ and symmetric $\left(v_{\mathrm{s}}\right)$ stretching motions are slightly shifted upward in PEI due to the presence of amino

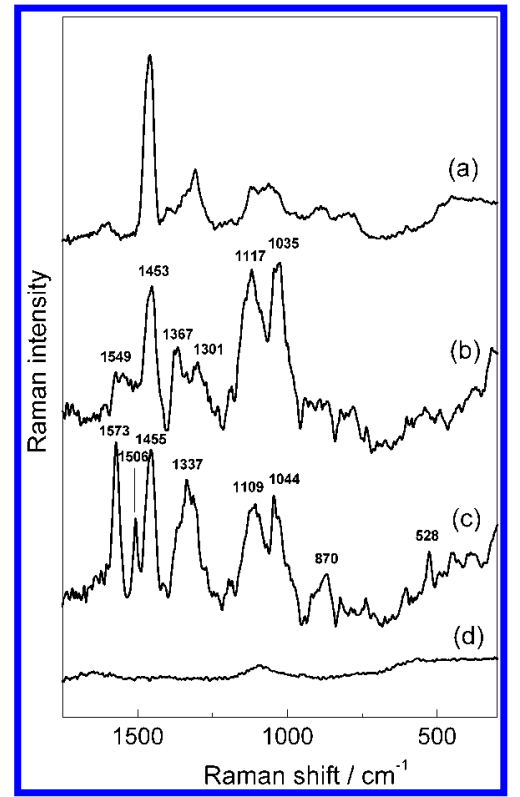

Figure 3. (a) Raman spectrum of PEI (50\% in water), (b) SERS of $\mathrm{PEI}\left(8 \times 10^{-5} \mathrm{M}\right)$, and $(\mathrm{c})$ SERS of PEI/plasmid complex $\left(8 \times 10^{-5}\right.$ $\mathrm{M}, 6.7 \mu \mathrm{g} / \mathrm{mL}$ ). (c) Control spectrum corresponding to the Ag colloid without adding PEI. Excitation at $1064 \mathrm{~nm}$.

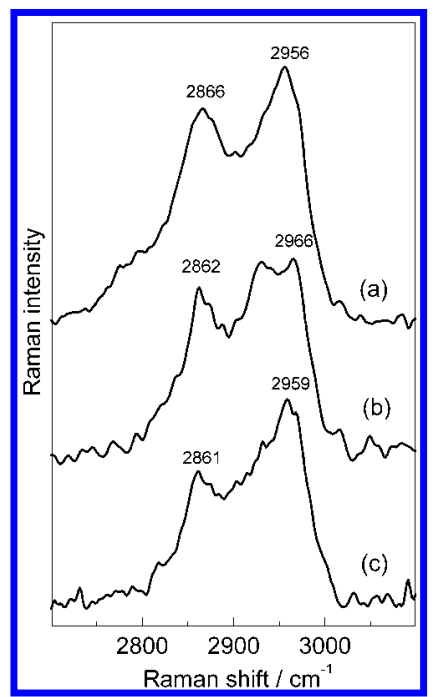

Figure 4. Same spectra of Figure 3 in the $3100-2700 \mathrm{~cm}^{-1}$ region.

groups in its structure. These modes appear at 2956 and 2866 $\mathrm{cm}^{-1}$ in the aqueous PEI, but undergo up and downward shifts, respectively, when the polymer is adsorbed on the surface. The decrease of the $v_{\mathrm{s}} / v_{\text {as }}$ ratio is related to the order/ disorder character of a polyethylene chain. ${ }^{27}$ In our case, we have observed an increase of this ratio that can be related to an increase of trans conformers in the aliphatic chain, in relation to the gauche ones, when the polymer is adsorbed on the metal; i.e., the polymer seems to adopt a more ordered conformation when it is adsorbed on the surface. On the other hand, a similar increase is also expected for the $v_{\mathrm{s}}$ mode by considering a perpendicular orientation of the $\mathrm{CH}_{2}$ plane with respect to the surface according to the SERS selection rules..$^{28}$

SERS of PEI at Different Excitation Wavelengths. SERS spectra at different excitation wavelengths reveal interesting changes (Figure 2). The SERS spectrum obtained at $782 \mathrm{~nm}$ (Figure 2d) differs considerably from that at 1064 nm (Figure 2c). In particular, we observed an enhancement 
of bands at 1523,1244,1031, 808, and $552 \mathrm{~cm}^{-1}$, which can be attributed to the amino moiety and the $\mathrm{C}-\mathrm{N}$ bond. ${ }^{22-24}$ In contrast, the SERS obtained by exciting at 514.5 $\mathrm{nm}$ is very weak (Figure 2e). We attribute this result to a resonant effect induced by a possible charge transfer due to the interaction of PEI with the surface. The existence of a charge transfer responsible for the resonant effect observed on changing the excitation wavelength is additional proof demonstrating the establishment of a strong interaction between amine groups and the metal leading to a change in the PEI protonation state. The intensification of bands corresponding to those groups through which the interaction takes place, i.e., the amino ones, when exciting at $782 \mathrm{~nm}$, indicates that this wavelength may be close to the resonance maximum of charge-transfer mechanism enhancement.

The band shifts observed at $1064 \mathrm{~nm}$ in comparison to those observed at $782 \mathrm{~nm}$ suggest the existence of different amino groups on the surface distinctly selected on varying the excitation wavelength, on one hand because of the existence of primary, secondary, and tertiary amino groups in the PEI polymer and on the other hand because these groups could be either adsorbed through a different mechanism to the surface (forming an ionic pair in an electrostatic interaction with negative charges existing on the surface or a coordination complex with the metal) or surrounded by aliphatic groups with a different conformation.

SERS of the PEI/Plasmid Complex. The SERS of the PEI/plasmid complex was examined at two different excitation wavelengths, 1064 and $514.5 \mathrm{~nm}$, to selectively study either the PEI polymer or the plasmid. We have seen that the SERS spectrum of the plasmid is very weak at $1064 \mathrm{~nm}$; thus the structural changes undergone by PEI are better seen at this wavelength. In contrast, the SERS of PEI is very weak when exciting at $514.5 \mathrm{~nm}$ (Figure 2e), and this line was the most appropriated one to follow structural changes undergone by the plasmid in the presence of PEI.

In Figure 3 the SERS spectrum at $1064 \mathrm{~nm}$ of PEI (Figure $3 \mathrm{~b}$ ) and its complex with the plasmid (Figure 3c) are compared. The main difference between both spectra is observed in the $1600-1500 \mathrm{~cm}^{-1}$ region, where two prominent bands are observed at 1573 and $1506 \mathrm{~cm}^{-1}$. As these bands are assigned to the amino groups, we suggest that these groups are directly involved in the interaction with DNA, as expected by considering an electrostatic interaction between both polymers. In particular a remarkable change in the protonation state of these groups is deduced. The above bands can be attributed to asymmetric and symmetric $\mathrm{NH}_{3}{ }^{+}$ deformations, usually appearing at 1625-1560 and 1550$1505 \mathrm{~cm}^{-1}$, respectively, ${ }^{29}$ although these bands can be also due to $\delta\left(\mathrm{NH}_{2}^{+}\right)$in protonated secondary amines or to $\delta$ $\left(\mathrm{NH}^{+}\right)$in protonated tertiary amines. ${ }^{29}$ Therefore, the appearance of the above bands in the SERS spectrum of the complex can be related to an increase of the protonation degree in PEI as a consequence of its interaction with DNA and induced by the electrostatic interaction with the negative phosphate groups in the plasmid. Nevertheless, other kinds of interactions different from the electrostatic ones are also possible such as hydrophobic interactions or hydrogen bonds. $^{30}$

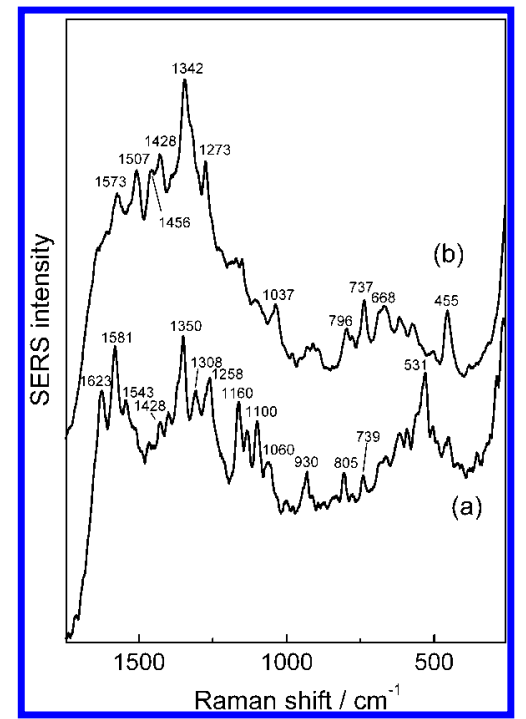

Figure 5. (a) SERS spectrum of the plasmid $(6.7 \mu \mathrm{g} / \mathrm{mL})$ and (b) SERS of PEl/plasmid complex $\left(8 \times 10^{-5} \mathrm{M}, 6.7 \mu \mathrm{g} / \mathrm{mL}\right)$. Excitation at $514.5 \mathrm{~nm}$.

The change in the protonation state of amino groups is also accompanied by a conformational change in the PEI polymer upon interaction with the plasmid. The conformational change is reflected in the $3100-2700 \mathrm{~cm}^{-1}$ region (Figure 4c) where a relative increase is observed for the asymmetric $\mathrm{C}-\mathrm{H}$ stretching at $2959 \mathrm{~cm}^{-1}$ in relation to the symmetric mode at $2861 \mathrm{~cm}^{-1}$. Since the $v_{\mathrm{s}} / v_{\text {as }}$ ratio is related to the order in the ethylene chain, i.e., to the number of trans versus gauche conformers, ${ }^{27}$ we deduced an increase of the disorder in the PEI linked to the plasmid. This disorder may be induced by the strong interaction established between the polymer and the plasmid and is also supported by the selective recognition of DNA topology demonstrated by PEI. ${ }^{31}$

Structural changes in the plasmidic DNA were followed by exciting at $514.5 \mathrm{~nm}$ (Figure 5). The SERS spectrum of the plasmid (Figure 5a) exhibits characteristic vibrational modes due to the different nucleic bases existing in DNA. In Table 1 we have summarized the assignments of the main Raman wavenumbers of the plasmid in accordance to the literature. ${ }^{32,33}$ DNA structural marker bands mainly appear in the $600-900 \mathrm{~cm}^{-1}, 32$ for this reason we show in Figure 6 the spectra of Figure 5 amplified in this region. The observation of two bands at 830 and $806 \mathrm{~cm}^{-1}$ in the SERS of the plasmid (Figure 6a), which can be attributed to the phosphate-ribose backbone, indicates the coexistence of both B-type and A-type DNA. The simultaneous presence of these structures has been found in a variety of DNAs including plasmids. ${ }^{34,35}$ The coexistence of both DNA structures is also corroborated by the presence of two bands at 683 and $663 \mathrm{~cm}^{-1}$, which are attributed to guanine residues forming part of B- and A-DNAs, respectively. ${ }^{32}$

The SERS of the PEI/plasmid is shown in Figure 5b. In comparison to the SERS spectrum of the plasmid (Figure $5 a)$, we observed a marked decrease of the bands corresponding to the plasmid except for the bands assigned to the adenine residue. In fact, the bands observed at 1342 and $737 \mathrm{~cm}^{-1}$ are clearly due to this base. ${ }^{36,37}$ Other bands observed at 1273 and $778 \mathrm{~cm}^{-1}$ are attributed to cytosine, ${ }^{36,38}$ 
Table 1. Wavenumbers $\left(\mathrm{cm}^{-1}\right)$ and Assignments of SERS Spectra of Plasmid and PEI/Plasmid Complexes.

\begin{tabular}{|c|c|c|}
\hline SERS of plasmid & SERS of PEl/plasmid & assignments $a, b$ \\
\hline 1623 & & $\mathrm{C}=\mathrm{O}$ in $\mathrm{C}, \mathrm{G}, \mathrm{T}$ \\
\hline \multirow[t]{2}{*}{1581} & & $\mathrm{G}, \mathrm{A}$ \\
\hline & 1573 & G, A/PEI \\
\hline \multirow[t]{2}{*}{1543} & & $\mathrm{G}, \mathrm{C}$ \\
\hline & 1507 & $\mathrm{~A} / \mathrm{PEI}$ \\
\hline 1465 & 1456 & R/PEI \\
\hline 1428 & 1428 & $A, G$ \\
\hline 1397 & & $\mathrm{~T}, \mathrm{~A}, \mathrm{G}$ \\
\hline 1350 & 1342 & A \\
\hline \multirow[t]{2}{*}{1308} & & $\mathrm{C}, \mathrm{G}, \mathrm{A}$ \\
\hline & 1273 & $\mathrm{C}, \mathrm{A}$ \\
\hline 1258 & & $C, A$ \\
\hline 1160 & 1168 & $\mathrm{R}$ \\
\hline 1130 & & $\mathrm{R}$ \\
\hline 1100 & 1108 & $\mathrm{P}\left(v_{\mathrm{as}}\right)$ \\
\hline 1060 & 1037 & $\mathrm{R} / \mathrm{P}$ \\
\hline 930 & 930 & $P$ \\
\hline 830 & 845 & $\mathrm{P} / \mathrm{R}$ \\
\hline \multirow[t]{2}{*}{805} & & $\mathrm{P} / \mathrm{R}$ \\
\hline & 796 & $\mathrm{P}\left(v_{\mathrm{s}}\right)$ \\
\hline 778 & 776 & $\mathrm{C}^{13}$ \\
\hline 740 & 736 & $A$ \\
\hline \multirow[t]{2}{*}{683} & 685 & G \\
\hline & 670 & $\mathrm{G}$ \\
\hline 662 & & $\mathrm{G}, \mathrm{T}$ \\
\hline 615 & 618 & \\
\hline 591 & 571 & \\
\hline 531 & & \\
\hline 450 & & \\
\hline
\end{tabular}

${ }^{a}$ A, adenine; C, cytosine; $G$, guanine; $T$, thymine; $R, 2^{\prime}$-deoxyribose; $\mathrm{P}$, phosphate. ${ }^{b}$ Assignments from refs 29 and 30 .

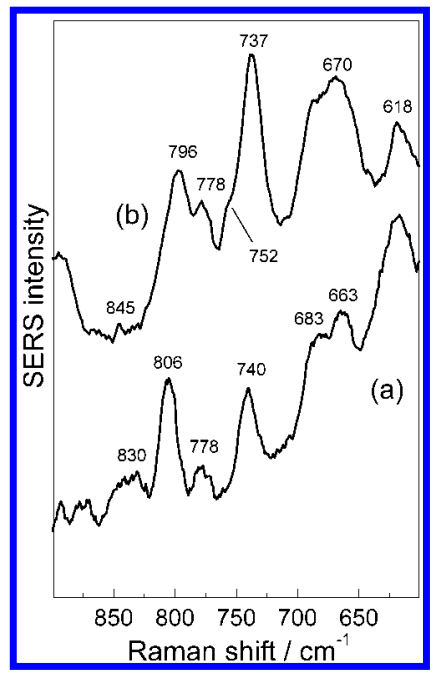

Figure 6. Same spectra of Figure 5 in the $900-600 \mathrm{~cm}^{-1}$ region.

while the bands appearing at 900-950 and $796 \mathrm{~cm}^{-1}$ are due to the phosphate-ribose backbone. ${ }^{32}$ The predominance of adenine bands in the SERS of the complex suggests that adenine-rich regions of the plasmid are mainly involved in the interaction with PEI. This is deduced from the shortrange character of SERS effect that predicts a larger enhancement for the molecular groups closer to the surface. Since PEI is strongly attached to the metal surface, it is supposed that those DNA bases which are more enhanced in the SERS spectrum are the most attracted by the polymer. On the other hand, downward shifts observed for the bands of adenine, from 1350 and 740 to 1342 and $735 \mathrm{~cm}^{-1}$, are attributed to a displacement of this residue from the metal surface to the polymer attracted by a stronger interaction with PEI. It is to note that in the spectrum of the complex, bands corresponding to PEI are now observable at 1573, 1507, and $1037 \mathrm{~cm}^{-1}$. These bands are very weak in the SERS of PEI alone (Figure 2e), but in the complex the bands are enhanced due to its interaction with the plasmid.

The $600-850 \mathrm{~cm}^{-1}$ region reveals interesting structural changes related to the plasmid backbone structure as a consequence of the complexation (Figure 6). For instance, a remarkable intensity decrease is observed for the band at $806 \mathrm{~cm}^{-1}$, related to A-DNA structure, while a prominent band is observed at $796 \mathrm{~cm}^{-1}$. The last band is attributed to the symmetric $\mathrm{O}-\mathrm{P}-\mathrm{O}$ stretching vibration, which is usually very strong in DNA in aqueous solution, ${ }^{32}$ and that is characteristic of a B-DNA structure. ${ }^{33}$ The presence of a weak band at $845 \mathrm{~cm}^{-1}$ is also related to the existence of such a structure in the complex with PEI. Therefore, a transition from A- to B-conformation in the plasmid when passing from the metal surface to the complex with PEI can be deduced. A similar conformational change is observed when calf thymus DNA passes from a ordered structure to a disordered one, ${ }^{39}$ and this is what probably occurs when the plasmid interacts with PEI. Changes in the plasmid structures also affect the guanine ring breathing bands which appear above $650 \mathrm{~cm}^{-1}$. In fact the $663 \mathrm{~cm}^{-1}$ band corresponding to the A-DNA structure is shifted to $670 \mathrm{~cm}^{-1}$, thus indicating the disappearance of the A structure in the complex in favor of the B-DNA one.

In addition to the change of DNA secondary structure, we have also investigated the possible change of the tertiary structure, i.e., the superhelicity, of the plasmid as a consequence of the interaction with PEI. In a Raman study carried out by Christens-Barry et al. on a supercoiled-extended plasmid transition, ${ }^{35}$ it is concluded that the major response of the helix backbone to the changes in the superhelicity of circular DNAs mainly involve the $\mathrm{C}-\mathrm{O}$ bond region and, in particular, the corresponding $\mathrm{C}-\mathrm{O}$ linkage between the $\mathrm{C}^{\prime}$ carbon and the phosphate group, in agreement also with the work by Eckstein et al. ${ }^{40}$ In our case, we have found important changes in the $1160-1000 \mathrm{~cm}^{-1}$ region, directly related to the ribose-phosphate moiety, along with the band at $796 \mathrm{~cm}^{-1}$ that is also assigned to this moiety, which suggests a change in the tertiary DNA structure upon complexation with PEI.

Christens-Barry et al. also found that the transition from the supercoiled structure to a linear one is accompanied by a relative increase of certain bands, namely, those appearing at $1458,1421,1336,1060$, and $755 \mathrm{~cm}^{-1}$. These bands may correspond to those observed in our plasmid/PEI complex at $1456,1428,1342,1050$ (as a shoulder of the $1037 \mathrm{~cm}^{-1}$ band), and $752 \mathrm{~cm}^{-1}$ (as a shoulder of the $737 \mathrm{~cm}^{-1}$ band which increases in the complex). Hence, we suggest that the complexation is accompanied by a transition of the plasmid to a more linear and open structure as a consequence of its interaction with PEI. The differences in the frequencies of 
our SERS spectra may be a consequence of the influence of the metal surface in the interaction with the complex. Hayashi et al. have also proposed that an increase of the $735 \mathrm{~cm}^{-1}$ adenine band could be associated to a linear structure,${ }^{39}$ and this is what we just observed in the SERS of the PEI/plasmid complex.

The involvement of adenine-rich plasmid regions in the interaction with PEI could be associated with the conformational changes occurring in the plasmid, as these regions seem to be the more susceptible ones to undergo a structural change that favor unwinding, due to the fact that they are termodinamicaly less stable. ${ }^{41}$

\section{Conclusions}

Raman spectroscopy is an useful technique to study conformational changes induced by adsorption of PEI on a metal surface as well as to study its complexation with plasmid DNA. PEI undergoes important conformational changes related to the protonation state and the order of ethylene groups in the polymer. The interaction with the $\mathrm{Ag}$ colloidal particles takes place through the amino groups, strongly attracted by the negative charge existing in the surface of these particles or directly linked trough coordination bonds with the metal. This interaction lead to a charge transfer between the surface and PEI which accounts for the resonant effect observed in the SERS spectra on varying the applied excitation wavelength.

The Raman study of the PEI/plasmid complex was carried out at different wavelengths in order to selectively study the conformational changes undergone by each component of the complex. At $1064 \mathrm{~nm}$ changes in PEI are evident, showing that both the protonation state and the conformation of PEI are modified in the presence of DNA. By exciting at $514.5 \mathrm{~nm}$ the spectrum is dominated by bands of the plasmid. Changes in the Raman spectra demonstrated evident structural modifications at different molecular levels. On one hand the DNA seems to adopt a more linear structure upon interaction with PEI. This change in the superhelicity of DNA chain is accompanied by a clear change in the backbone structure from A- to B-DNA as a consequence of the interaction with the polymer. The structural changes seem to be more intense in A-rich sequences, and this is related to the lower thermodinamical stability of this part of DNA. Thus, this preliminary study affords very promising structural information in the analysis of recognition problems between large-sized polymers with high interest in processes of biological significance such as gene delivery.

Acknowledgment. This work has been supported by Dirección General de Enseñanza Superior e Investigación Científica, Project number BFM2001-2265, and the Comunidad de Madrid, project number 07M/0111/2000. One of us also thanks CSIC and BIOTOOLS for their finantial support.

\section{References and Notes}

(1) Behr, J. P. Tetrahedron Lett. 1986, 27, 5861.

(2) Behr, J. P.; Demeneix, B. A.; Loeffler, J. J.; Perez-Mutul, J. Proc. Natl. Acad. Sci. U.S.A. 1989, 86, 6982.
(3) Demeneix, B. A.; Goula, D.; Benoist, C.; Remy, J. S.; Behr, J. P. In Theory and practice of using polycationic amphiphiles and polymers for in vitro and in vivo gene transfer; NATO ASI Ser., vol. H, 105(Gene Therapy); Springer-Verlag: Berlin, 1998.

(4) Suh, J.; Paik, H. J.; Hwang, B. K. Bioorg. Chem. 1994, 22, 318.

(5) Han, S.; Mahato, R. I.; Sung, Y. K.; Kim, S. W. Mol. Ther. 2000, 2, 302.

(6) Fleischmann, M.; Hendra, P. J.; McQuillan, A. J. Chem. Phvs. Lett. 1974, 26, 163.

(7) M. Moskovits, Rev. Mod. Phvs. 1985, 57, 783.

(8) Burstein, E.; Chen, Y. J.; Chen, C. Y.; Lundquist, S.; Tosatti, E. Solid State Commun. 1979, 29, 567.

(9) Furtak, T. E. J. Electroanal. Chem. 1983, 150, 375.

(10) Munro, C. H.; Smith, W. E.; Garner, M.; Clarkson, J.; White, P. C. Langmuir 1995, 11, 3712.

(11) Goula, D.; Erbacher, P.; Wasowicz, M.; Levi, G.; Abdallah, B.; Demeneix, B. A. Gene Ther. 1998, 5, 712.

(12) Baker, A.; Saltik, M.; Lehrmann, H.; Killisch, I.; Mautner, V.; Lamm, G.; Christofori, G.; Cotten, M. Gene Ther. 1997, 4, 773.

(13) Meunier-Durmont, C.; Grimal, H.; Sachs, L. M.; Demeneix, B. A.; Forest, C. Gene Ther. 1997, 4, 808.

(14) Zanta, M. A.; Boussif, O.; Adib, A.; Behr, J. P. Bioconiugate Chem. 1997, 8, 839 .

(15) Lee, P. C.; Meisel, D. J. Phys. Chem. 1982, 86, 3991.

(16) Sanchez-Cortes, S.; García-Ramos, J. V.; Morcillo, G., J. Colloid Interface Sci. 1995, 175, 358.

(17) Sanchez-Cortes, S.; García-Ramos, J. V.; Morcillo, G.; Tinti, A., J. Colloid Interface Sci. 1995, 175, 358.

(18) Boussif, O.; Lezoualc'h, F.; Zanta, M. A.; Mergny, M. D.; Scherman, D.; Demeneix, B. A.; Behr, J.-P. Proc. Natl. Acad. Sci. U.S.A. 1995, 92, 7297.

(19) Hendra, P. J.; Agbenyega, J. K. The Raman Spectra of Polymers; John Wiley \& Sons: Chichester, 1993.

(20) Brucker Analytische Messtechnik GMBH Library, 1995.

(21) Buckingham, D. A., Jones, D. Inorg. Chem. 1965, 4, 1387.

(22) Bellanato, J. Spectrochim. Acta 1960, 16, 1344.

(23) Berg, R. W.; Rasmunsen, K. Spectrochim. Acta 1973, 29A, 37.

(24) Watt, G. W.; Klett, D. S. Spectrochim. Acta 1964, 20, 1053.

(25) Creighton, J. A. Selection Rules for Surface-Enhanced Raman Spectroscopy. In Spectroscopy of Surfaces; Clark, R. J. H., Hester, R. E., Eds.; John Wiley \& Son: Chichester, 1988.

(26) Chaufer, B.; Rabiller-Baudry, M.; Bouguen, A.; Labbé, J. P.; Quémarais, A. Langmuir 2000, 16, 1852.

(27) Zerbi, G.; Del Zoppo, M. Vibrational Spectroscopy as a Probe of Structural Order/Disorder in Chain Molecules and Polymers in Modern Polymer Spectroscopy; Zerbi, G., Ed.; Wiley-VCH: New York, 1999.

(28) Moskovits, M.; Suh, J. S. J. Am. Chem. Soc. 1985, 107, 6826.

(29) Colthup, N. B.; Daly, L. H.; Wiberly, S. E. Introduction to Infrared and Raman Spectroscopy, 2nd ed.; Academic Press: New York, 1975.

(30) Clark, S. L.; Hammond, P. T. Langmuir 2000, 16, 10206.

(31) Bronich, T.; Nguyen, H. K.; Eisenberg, A.; Kabanov, A. V. J. Am. Chem. Soc. 2000, 122, 8339.

(32) Peticolas, W. L.; Kubasek, W. L.; Thomas, G. A.; Tsuboi, M. Nucleic Acids. In Biological Applications of Raman Spectroscopy; Spiro, T. G., Ed.; Wiley-Interscience: New York, 1987; Vol. 1.

(33) Thomas, G. A.; Tsuboi, M. Adv. Biophvs. Chem. 1993, 3, 1.

(34) Vasmel, H. Biopolvmers 1985, 24, 1001.

(35) Christens-Barry, W. A.; Martin, J. C.; Lebowitz, J. Biopolymers 1989 , 28,1515

(36) Lord, R. C.; Thomas, G. J. Spectrochim. Acta 1967, 23A, 2551.

(37) Sanchez-Cortes, S.; García-Ramos, J. V. J. Mol. Struct. 1992, 274, 33.

(38) Sanchez-Cortes, S.; García-Ramos, J. V. J. Raman Spectrosc. 1992, 23,61 .

(39) Hayashi, H.; Nishimura, Y.; Tsuboi, M.; Sekimuzi, K.; Nakanishi, Y.; Natori, S. Biopolymers 1985, 24, 1107.

(40) Eckstein, R.; Jovin, T. M. Biochemistry 1983, 22, 4546.

(41) Benham, C. J. Proc. Natl. Acad. Sci. U.S.A. 1979, 76, 3870.

BM015640O 